\title{
Problemas de patrimônio como problemas de gênero: disjunções entre feminismo e cultura popular na Festa de Santo Antônio em Barbalha (CE) ${ }^{1}$
}

Roberto Marques²

\section{Resumo}

0 artigo analisa disjunções e conjunções existentes entre as ações dos feminismos no Cariri e o imaginário espacial que modula a patrimonialização da Festa do Pau de Bandeira de Santo Antônio, na cidade de Barbalha (CE). No ano de 2019, durante o cortejo de grupos de cultura popular que antecede a Festa do Pau da Bandeira, aconteceu a sexta Marcha das Mulheres. Ao longo do percurso, participantes da marcha foram continuamente interpeladas por representantes da organização institucional da Festa. A ação dos organizadores acionava formas de localização do movimento de mulheres, uma compreensão nativa dos debates sobre gênero e sobre a cultura popular naquela manifestação. Pensamos a expressão desse conflito social como disputa entre diferentes projetos para a região do Cariri cearense, para os debates sobre gênero e para a vida das mulheres na região. A patrimonialização da Festa e seus personagens acessam uma romantização do mundo rural incompatível com a denúncia da morte de mulheres na região do Cariri pelos feminismos locais, embora ambas as narrativas estejam conectadas à ideia de um Brasil rural, atávico, distante da cidadania e urbanidade. As fricções ocorridas na Festa de Santo Antônio relembram, portanto, imagens que circulam em momentos em que grupos à margem do imaginário nacional brasileiro empunham símbolos diacríticos das ideias de participação política e memória nacional. Tensões acessadas como clichês de uma utopia generalizante de abrigo à diversidade de demandas compostas pela e para a nação.

\section{Palavras-chave}

Feminismos. Patrimônio. Cultura Popular.

\begin{abstract}
The article analyzes disjunctions and conjunctions between the actions of feminisms in Cariri and spatial imagery that modulates the cultural heritage state of the Festa do Pau da Bandeira in Barbalha (Ceará). In 2019, during the procession of popular culture groups that precedes the Festa
\end{abstract}

\footnotetext{
1 Resultado parcial de pesquisa de pós-doutorado junto ao Núcleo Pagu/UNICAMP, sob orientação de Regina Facchini. Versões desse artigo foram apresentadas na XIII Reunião de Antropologia do Mercosul, em Porto Alegre- RS e no X Artefatos da Cultura Negra, em Crato- CE.

2 Professor do Programa de Pós-Graduação em Sociologia (PPGS) da UECE. E-mail: enleio@yahoo.com.br.
} 
da Pau da Bandeira, the sixth Women's March took place. Along the route, marchers were continuously interpellated by the employees of the event's organization committee. The organizers acted to find ways to dislocate the women's movement, a native understanding about gender debate and popular culture in that demonstration. We understand this social conflict expression as a dispute between different projects for the Cariri area, the gender debate, and the lives of women in that area. The recognition of the of Festa de Santo Antônio and its characters as cultural heritage access a romanticization of the rural world, which is incompatible to the reporting of women's death in the Cariri area by local feminisms, although both narratives are connected to the idea of a rural, atavistic Brazil, away from citizenship and urbanity. The frictions that took place in the Festa de Santo Antônio remind us, therefore, of images that circulate in moments which groups on the margin of the Brazilian national imagination wield diacritical symbols to the ideals of political participation and national memory. Tensions accessed as clichés of a generalizing utopia to shelter the diversity of demands composed by and for the nation.

\section{Keywords}

Feminisms. Cultural Heritage. Popular Culture.

\section{Introdução}

Na manhã de 02 de junho de 2019, militantes próximos à Frente de Mulheres dos Movimentos do Cariri começaram a se aglomerar na calçada do Solar Maria Olímpio, nas imediações da Praça Figueira Sampaio, centro da cidade de Barbalha. Diante do casario colonial, era possível perceber membros de diferentes coletivos articulados pela Frente conversando pelas calçadas enquanto aguardavam o início da sexta Marcha das Mulheres. A marcha acompanharia o cortejo de grupos populares que usualmente ocorre nas manhãs do primeiro dia da Festa do Pau da Bandeira de Santo Antônio, saindo da Igreja Matriz até um palanque montado na Praça Dr. João Figueiras Teles, em frente à Igreja do Rosário. Ali, estariam políticos locais, estaduais e autoridades eclesiásticas.

Em meio à multidão que assistia e participava das calçadas da rua do Vidéo, militantes da Frente denunciavam casos de violência doméstica e feminicídio frequentes naquela cidade e na região do Cariri. Apontavam a inexistência de equipamentos públicos de combate à desigualdade de gênero em Barbalha, bem como os retrocessos estabelecidos pelo governo Bolsonaro aos direitos de trabalhadores e trabalhadoras rurais naquele ano de 2019. À frente da primeira 
faixa que marcava a presença da Frente no cortejo de grupos populares na Festa, seguia um grupo de reisado. Atrás, crianças paramentadas como vaqueiros, cangaceiros ou outra personificação do imaginário rural popular nordestino.

Havíamos andado três ou quatro quarteirões quando um funcionário uniformizado, falando em nome dos organizadores da Festa em Barbalha, adentrou o cortejo e passou a interagir com algumas das militantes. Afobado, explicava às mulheres, com microfones em punho seguidas por caixas de sons e dezenas de militantes, que sua marcha deveria andar atrás dos grupos folclóricos, não entre eles. À medida que a marcha avançava em direção ao palanque, nosso interlocutor parecia mais aflito. Alheio às temáticas sublinhadas pelo movimento de mulheres, tentava evitar um possível encontro entre o movimento social e as autoridades que estariam no palanque assombreado alguns metros adiante.

Perceber a dimensão alegórica da textualização desse conflito (CLIFFORD, 2002 [1986]) elicia questões relevantes sobre possíveis conjunções e disjunções (BRAH, 2006) entre movimentos sociais e cultura popular no Cariri cearense. Por que as mulheres marcham durante a Festa do Pau da Bandeira em Barbalha? Por que marcham entre os grupos de cultura popular? Que forma vem assumindo o cortejo desses grupos na manhã de abertura da Festa tombada pelo Instituto do Patrimônio Histórico e Artístico - IPHAN?

Para James Clifford (2002), a escrita da cultura aciona alegorias em sua forma e conteúdo, embutindo "conteúdos morais, ideológicos e mesmo cosmológicos" na descrição de "acontecimentos culturais reais" (p. 63). Buscamos demonstrar adiante como as ideias persistentes e multifacetadas de cultura popular, gênero e Cariri demandam ações, práticas e comportamentos psicológicos de agentes socialmente localizados como condição e efeito da textualização da cultura. Essas formas expressivas aparecem ora de forma dispersa, ora excessivamente estereotipadas, no conflito social descrito nos parágrafos iniciais deste artigo e retomado mais adiante.

Clifford (2002) encontra um paralelo para a dimensão alegórica da textualização da cultura na noção de performance social e seu poder expressivo em Victor Turner (1987, 2015 [1982]) ${ }^{3}$. Ao condensar histórias míticas e de senso comum, as performances confeririam aos processos sociais uma retórica, uma forma de enredo, um significado (CLIFFORD, 2002, p. 63).

\footnotetext{
${ }^{3}$ Para pensar as diferentes implicações teórico-metodológicas das noções de performance e drama social, ver Cavalcanti (2007) e Silva (2005).
} 
A partir da noção de dramas sociais, Turner (1987) define "unidades aparentes de processos sociais não harmônicos ou desarmônicos reveladas em situações de conflito ${ }^{\prime \prime}$ (p. 74). Dessa forma, destaca padrões normativos e regularidades na conformação da cultura; enaltecendo o potencial de transformação e distanciamento reflexivo da estrutura social a partir de momentos rituais extraordinários ${ }^{5}$.

Nosso intuito aqui é qualificar o conflito entre agentes distintos, associandoos a formas expressivas que encenam o Cariri como espaço particular ao longo do cortejo de grupos populares e da Festa de Santo Antônio em Barbalha. As ações, estados e comportamentos psicológicos desses agentes funcionariam "não apenas para dar ordem ao universo que habitam, mas criativamente para também fazer uso da desordem (...) ao questionar os princípios axiomáticos anteriores que se tornaram um entrave para o entendimento e manipulação de coisas contemporâneas" (TURNER, 2015, p. 29), a exemplo de outras vivências descritas por Turner em sociedades complexas (TURNER, 1987, 2015). Examinaremos, portanto, diferentes regimes autorais internos às construções narrativas (CAVALCANTI, 2007, p. 29) dos agentes na Festa de Santo Antônio, condensando o conflito social pela performance legítima e legitimável de ocupar a rua.

Paulo Raposo (2014) chama a atenção para as novas configurações da ocupação dos espaços públicos pelos movimentos sociais a partir de 2009. Segundo o autor, o ato de "tomar a rua" expandiu "(...) as potencialidades dos movimentos sociais partilharem e trocarem informações para além do espaço que lhes era reservado pelas mídias convencionais" (p. 92). Aliadas a tecnologias recentes de distribuição e produção de conteúdo, performances públicas revelam mais que a necessária tensão sobre a gestão de políticas institucionais ou embates por objetivos socioeconômicos. São agora essencialmente "embates culturais" de definição das regras do jogo. Tais regras implicam um "sistema expressivo" (CRUCES, 1998), que comunica e identifica a um só tempo a dinâmica que legitima a ocupação público por grupos, os espaços por eles ocupados e os limites da ação e participação democrática. Para Cruces (1998), protestos públicos são exercícios poéticos e políticos de imaginação. Um exercício expressivo de ocupação da cidade, em que uma

\footnotetext{
${ }^{4}$ No original: "I define social dramas as units of aharmonic os disarmonic social process, arising in conflit situations."

${ }^{5}$ De acordo com Cavalcanti (2007, p. 128-129), ao salientar a dimensão dramática da vida social, Turner a um só tempo se aproxima e se distancia de temas clássicos da antropologia social britânica e dos estudos orientados por Max Gluckman então.
} 
multiplicidade de grupos desenvolve "distintas encenações do que são, do que têm sido e do que almejam ser" (p. 27).

Atenta aos jogos de nomeação que reivindicam ações e disputas políticas como "movimentos democráticos", Judith Butler (2018) insiste que diferentes formas de assembleia se estabelecem como personificações plurais daquilo que se reivindica como "povo" ou como "ação política legítima". Para a autora, esse necessário exercício de liberdade supera a própria ação da esfera judicial à medida que ratifica agenciamentos de participação inéditos. Mais uma vez, performances públicas estabelecem as próprias regras do jogo. Desse jogo se alimentam os movimentos que apoiam grupos estigmatizados ou distanciados dos direitos sociais. À medida que a mensagem se expande para um público mais amplo e indefinido, protestos públicos são capazes de convencionar formas de participação e formação de comunidades (RANCIÈRE, 2009). Irmanam-se assim às problemáticas apontadas por Yúdice (2013) e Hershmann (2011) sobre as formas de identificação e definição de si a partir de plataformas não presenciais. À medida que materializam expressões que se estendem para além de suas fronteiras usuais de participação e recepção, compete aos movimentos sociais a comunicação e significação contínua daquilo que são, de onde vêm e do espaço que ocupam a fim de expressar o que almejam.

Tais formulações serão aqui testadas a partir da presença e ação da Frente de Mulheres dos Movimentos do Cariri na Festa de Santo Antônio, em Barbalha. Esse coletivo vem constituindo uma frente de ação política multifacetada ao longo da última década, tornando-se agente fundamental em ações relacionadas ao acesso da população negra a políticas públicas; apoio às numerosas vítimas de violência de gênero na região do Carirí; planejamento, instalação e avaliação de políticas públicas relacionadas à moradia, educação e saúde; ações educativas junto a grupos considerados vulneráveis; negociações diretas com gestores; organização de marchas de visibilização de lutas na região do Cariri, entre tantas outras ações.

Ao longo dos últimos três anos, tenho pensado como tais ações deslocam significados sobre a espacialidade conhecida como região do Cariri, um conjunto de 28 municípios distante cerca de 600 quilômetros dos principais centros urbanos do Nordeste brasileiro. Assume-se aqui a relevância da força performativa da ocupação pública por lutas políticas, aliada à materialização de marcadores sociais da diferença, significados pela aparição contínua e significativa dos corpos das lideranças dos movimentos (MARQUES, 2019).

${ }^{6}$ Ver: Quirino, Marques e Araújo (2013), Marques (2013; 2015a). 
A um só tempo, a ação dessas agentes torna visíveis gramáticas particulares de ação nos movimentos feministas e a tematização do Cariri como espaço criado sob os signos da tradição e passado rural, potencializando sua ressignificação (LUNA, 2018). Possivelmente, apenas um movimento com fronteiras de identificação fluidas, ações pulverizadas e marcadores sociais abrangentes possa lidar com as limitações dessas gramáticas em espaços periféricos como o Nordeste brasileiro.

Tentaremos demonstrar isso a partir da ação da Frente na marcha ocorrida na cidade de Barbalha durante o cortejo de grupos populares que antecede o ritual do carregamento do Pau da Santo Antônio na festa do padroeiro dessa cidade no Cariri cearense. Dividimos nossa exposição em três partes: na primeira delas, esboçamos questões de significação do Cariri como espaço. Por aliarem significados tecidos ao longo dos últimos três séculos sobre sertão; mundo rural e tradição, os jogos de apagamento e inflação de significados que compõem o Cariri como espaço unitário parecem encontrar na Festa do Pau da Bandeira de Santo Antônio em Barbalha uma forma de expressão exemplar. Nossa descrição do espaço se entrelaça, portanto, aos discursos sobre memória coletiva e patrimonialização da Festa. Na segunda parte do texto, descrevemos a construção de memória sobre o espaço a partir da Festa como significação de corpos e ações dotadas de gênero e origem social. Descrevemos, portanto, performatividades de gênero capitaneadas pela e a partir da Festa.

Ressaltamos ao longo do texto distintas agências sobre as narrativas de gênero presentes na Festa: enquanto na memória usual da Festa de Santo Antônio mulheres são definidas pela busca de parceiros para o matrimônio; a Frente de Mulheres do Cariri busca ressignificar as relações de gênero e as dizibilidades sobre a região denunciando a desigualdade e violência de gênero. O embate entre o discurso hegemônico que compõe a memória da Festa a partir das relações de gênero e a denúncia das violências experienciadas pelas mulheres no Cariri compõe uma disputa pelo espaço, aqui descrita desde o conflito social expresso pela presença da Frente de Mulheres já esboçado e descrito pormenorizadamente.

Sentidos de significação e legitimação da ocupação do espaço público pelos grupos populares e pelos movimentos sociais parecem ter seus sentidos adensados a partir do embate. Ao mesmo tempo, conjunções e disjunções usuais entre as formulações sobre o povo nos grupos de cultura popular e do povo no movimento feminista ganham novas nuanças, fazendo-nos refletir sobre a dinâmica entre espaços, os dispositivos de definição do Cariri como 
espaço unificado e limites das gramáticas que compõem a dinâmica dos embates para sua definição.

\section{Caleidoscópio Cariri}

Em conjunto com Juazeiro do Norte e Crato, a cidade de Barbalha compõe o que é usualmente descrito como centro econômico, político e cultural da região do Cariri . A partir de 2009, as três cidades juntamente com Caririaçu, Farias Brito, Jardim, Missão Velha, Nova Olinda e Santana do Cariri passam a ser reconhecidas como Região Metropolitana do Cariri (QUEIROZ, 2014).

Martins (2003) chama atenção ao fato de o Cariri comunicar-se com o restante do Nordeste, do Brasil e do mundo, a partir das personagens Luiz Gonzaga, Padre Cícero e do poeta popular Patativa do Assaré. Deslocamentos contínuos na significação desse espaço mostram a complexidade das disputas em torno de sua dizibilidade ${ }^{8}$, compondo guerras culturais com repercussões econômicas, políticas e no cotidiano das populações que por ali circulam ou habitam. De forma sintética, poderíamos dizer que se trata de um território inventado à luz da ideia de tradição. O conjunto difuso usualmente chamado cultura popular emerge, portanto, como anteparo simbólico que alegoriza a região, seu território, sua população e as relações socioculturais ali presentes ${ }^{9}$.

Nas textualizações do Cariri como espaço unificado, chama a atenção a variedade de experiências dispersas estabelecidas a partir da conjunção entre narrativas espaciais e usos da categoria "povo" precipitadas pelo termo cultura popular (HOBSBAWN,1997; ANDERSON,1989; BURKE,1989). Essa

\footnotetext{
7 Barbalha, Crato e Juazeiro do Norte possuem, respectivamente, 60.781, 132.123 e 274.207 habitantes. O chamado Triângulo Crajubar concentra as maiores zonas urbanas e empresariais da região, com destaque para Juazeiro do Norte. Queiroz (2014) trata o conjunto de municípios como relevante área de habitação e fluxo populacional. Política e economicamente estratégico, portanto, no que tange à concentração de eleitores e políticas públicas.

${ }^{8}$ Aproximamo-nos aqui ao argumento de inspiração foucauldiana utilizado por Edward Said (1990 [1978]) de que o espaço é uma materialização de relações de poder instituída a partir de disputas sociais em que textos, obras e autores assumem, ou não, poder referencial. Argumento semelhante é utilizado por Albuquerque Jr. (2001 [1999]), ao definir o Nordeste brasileiro como "repetição de determinados enunciados, que são tidos como definidores do caráter de região e de seu povo" (p. 24).

9 Sobre a variedade de materializações e percursos institucionais referentes às manifestações atualmente reconhecidas como cultura popular no Cariri, ver: Slater (1982); Carvalho (1999); Nunes (2014); Lima (1985); Melo (2010); Alegre (1994); Gonçalves (2013); Andrade Filho (1991), Grangeiro (2013), Barroso (2013); Cariry e Barroso (1982); Rocha (2019).
} 
sobreposição funciona como artifício para a legitimação de uma comunidade imaginada (ANDERSON, 1989) à luz do modelo estado- nação.

Elencar distintas formas de circulação econômica; projetos políticos e articulações simbólicas que se impõem na textualização do Cariri nos relembra que o espaço não é apenas um cenário que ampara ações de sujeitos distintos. Ele é também um dado material da organização do pensamento e da dinâmica entre lugares. E, como tal, posto a serviço de jogos de poder.

É possível localizar notas sobre o conjunto difuso hoje descrito como cultura popular no Cariri desde a presença das expedições científicas no Brasil durante o século XIX. Em seus escritos de viagem à cidade de Crato, o naturalista Francisco Freire Alemão (2007 [1860]) ressaltou a "quantidade de pobres, de órfãos, de aleijados, de cegos, de presos da cadeia (...) a pedir esmolas, de joelho e chorando" (p. 14). Dando continuidade a seus relatos sobre a região, descreveu as missas e os festejos no adro da igreja, cheios de mulheres com lenços ou xales brancos sobre a cabeça, e a feira "topetada de gente" (p. 20), com "grande rumor e gritos de rezas de rapazes, crianças e estalos de fogos da China, atirados no meio do povo" (p. 19).

Em 1838, o naturalista britânico George Gardner descreveu as Bandas Cabaçais ${ }^{10}$ presentes nos folguedos ao sul do Ceará. Diz Gardner (1942 [1846]:

Durante minha estada em Crato celebrou-se o festival de Nossa Senhora da Conceição, precedido de nove dias de regozijo a expensas de vários indivíduos nomeados festeiros. Em todo o período da novena (...) o pequeno destacamento de soldados da Vila sustentou um fogo nutrido de dia e de noite. Com estas descargas, com as procissões e luminárias, com o estouro de fogos de artificio e os disparos de um pequeno canhão em frente da igreja, a Vila reboava incessantemente. (...) encaminhei-me pelas sete horas para a igreja diante da qual grande número de bandeirolas flutuavam em mastros e duas grandes fogueiras crepitavam. No terraço em frente do templo, ondulava grande massa humana e meiadúzia de soldados disparavam, a espaços, seus mosquetes. A pouca distância tocava uma banda de música, dois pífanos e dois tambores, música da peor categoria, a correr parelhas com os fogos de artifício então exibidos. (p. 160)

Em 1958, um dos principais articuladores do Instituto Cultural do CaririICC ${ }^{11}$, o intelectual local J. de Figueiredo Filho contrastou a depreciação dos

\footnotetext{
${ }^{10}$ Chamam-se bandas cabaçais conjuntos musicais formados por uma zabumba; um pífaro e um triângulo.

11 O Instituto Cultural do Cariri é uma agremiação político-literária fundada em 1953, presente
} 
folguedos e banda locais pelo naturalista escocês à percepção do pesquisador austríaco radicado em São Paulo, Martin Braunwieser. O então membro da Missão de Pesquisas Folclóricas enviada ao Norte e Nordeste pelo Departamento de Cultura da Prefeitura de São Paulo descreveu as Bandas Cabaçais em artigo de 1946, publicado no Boletim Latino-americano de Música, da seguinte forma:

Não há coisa mais linda do que uma cabaçal no sertão. Durante a viagem a Tacararu (Pernambuco), vi uma [banda] cabaçal tocando em frente a uma pequena capela, no campo (...). De longe ouvia-se o ritmo marcial dos zabumbas, convidando e chamando o povo para ir à capela (BRAUNWIESER apud FIGUEIREDO FILHO, 1955, p. 107).

Posteriormente, referindo-se ao instrumento musical chamado pife, Braunwieser (apud FIGUEIREDO FILHO, 1955) descreve "um som todo especial, um tanto agudo, melancólico, amoroso, lembrando pela altura nosso flautim" (p.107).

A colagem de percepções opostas entre um intelectual europeu, interessado na coleta de fauna e flora particulares das províncias do Norte brasileiro, e um musicólogo, curioso pelas particularidades na formação cultural brasileira ${ }^{12}$, demonstra que a descrição das manifestações culturais presentes no Cariri potencializam narrativas marcadas por projetos político-intelectuais distintos. Torna-se improvável, portanto, qualquer formulação geral capaz de prever a complexa tessitura entre as circunstâncias de produção dessas narrativas, seus distintos mediadores e a capacidade de agência desses mediadores e de suas obras. Restaria aos interessados levantar essa confluência de fatores caso a caso, a fim de não cristalizar uma ideia de Cariri, sob o risco de perpetuar relações de poder expressas em dizibilidades específicas, muitas vezes assumidas como verdadeiras a despeito do (re)conhecimento das circunstância que produziram tais dizibilidades (MARQUES, 2015b).

À luz de hoje, esses relatos parecem descrever um território coeso, alegoria da ocupação territorial a partir dos grandes latifúndios, das relações de trabalho características da monocultura de cana-de-açúcar, das experiências de migração de nordestinos em busca de trabalho. Invariavelmente, esse conjunto

ainda hoje na cidade de Crato- CE (VIANA, 2014; SEMEÃO, 2011).

12 Para pensar as relações entre identidade nacional e cultura popular no Brasil entre as décadas de 1930 e 1950, ver Cavalcanti et al. (2012 [1988]), Cavalcanti e Vilhena (2012 [1990]), Vilhena (1997). Para pensar o debate sobre música popular e identidade nacional na mesma época, ver Assis e Godoi (2016). 
é alinhado à religiosidade popular e lazer presentes nos sítios da Chapada do Araripe. Tal conjunto não vem passando despercebido a projetos intelectuais que espacializam nossa percepção do mundo, revisitando oposições relevantes na formação das Ciências Sociais, tais como rural e urbano; comunidade e sociedade, cultura popular e cultura erudita ${ }^{13}$.

Dado seu poder referencial, que formas narrativas e expressivas a conjunção entre povo e espaço vem assumindo na Festa do Pau de Santo Antônio em Barbalha?

\section{Trânsitos e marcadores em ebulição}

Para Souza (2000), o uso do termo festa para descrever a expressão religiosacultural anual em meados de julho em Barbalha remonta aos anos 1960-70.

Antes existia apenas o Cortejo do Pau da Bandeira de Santo Antônio. Este teve início em 1928, por iniciativa do vigário Pe. José Correia de Lima, que se inspirou no costume popular existente em Barbalha de hastear a bandeira do santo festejado durante as festas juninas e ocasião de renovações (SOUZA, 2004, p. 65).

Ao descrever as transformações mais relevantes ocorridas ao longo da Festa, o autor (2000) chama a atenção para os expedientes de carnavalização e folclorização. Define como carnavalização o processo ocorrido a partir dos anos 1940, década em que o cortejo do Pau de Santo Antônio se transformou em um momento festivo, envolvendo comida; disputas lúdicas e interação entre homens que carregam o Pau; acompanhamento do cortejo por bandas cabaçais e abundância de bebida, a chamada Cachaça do Vigário. Folclorização, enfim, seriam os esforços empreendidos a partir de 1973 pelo poder público municipal e a paróquia, que resolveram "juntar suas forças com o objetivo de transformar a festa de Santo Antônio num evento religioso de cunho folclórico-artísticocultural, passando a estimular 'o artesanato, a culinária típica e as danças e folguedos populares'”. (NEVES apud SOUZA, 2000)

Tais expedientes institucionalizam a festa, precipitando seu processo de patrimonialização e salvaguarda pelo IPHAN a partir dos anos 2000. O levantamento de material realizado compreende um acervo de mais de 3 mil

${ }^{13}$ Sobre a relação entre Cariri e projetos intelectuais que acessam a noção de mundo rural, ver: Figueiredo Filho (1960); Pinheiro e Figueiredo Filho (1953); Menezes (1985); Vieira (2000); Marques $(2008,2015)$. 
registros da Festa, como entrevistas; fotografias; matérias em periódicos (SOARES; SILVA, 2013, p. 6).

No texto apresentado pelo IPHAN-CE como dossiê de registro da Festa do Pau de Bandeira de Santo Antônio, há referências constantes à dificuldade de mediar as disputas sociais entre os múltiplos agentes que compõem a Festa, o que teria complexificado a função institucional do órgão. As tensões descritas a partir da experiência do IPHAN na cidade de Barbalha parecem incompatíveis com a construção de uma imagem totalizante das expressões que cercam os festejos. A despeito disso, imagens reiteradas e de fácil circulação dos carregadores do pau; dos grupos de cultura popular e seus artefatos ou da sobreposição entre Festa e experiência religiosa parecem pródigas em mobilizar marcadores sociais, definindo uma gramática de trânsitos e lugares sociais comunicados a partir da Festa do Pau de Santo Antônio. Observemos a reiteração de lugares comuns da Festa tal como presente no próprio Dossiê do IPHAN:

(...) No domingo em que ocorre o carregamento e hasteamento do pau da bandeira, logo pela manhã, por volta de cinco horas, alguma movimentação já vai ocorrendo, sobretudo o som inconfundível das bandas cabaçais que principiam a trilha de um roteiro cujo propósito central é construir a ideia de um espaço que remete os expectadores a expressões que supostamente aludem a noções como "cultura brasileira" e "cultura popular".

Outros tantos folguedos se posicionam e vão tomando conta do espaço; sob o sol a pino e a cumplicidade retumbante da Igreja Matriz e do casario antigo, os sons, movimentos e coloridos das manifestações, além do exotismo de tantas presenças ilustres para quem inevitavelmente os olhares convergem, marcam o tom da diferença e da mistura organizada. No mesmo domingo no qual os grupos de folguedos se manifestam dispersos pelas adjacências do largo onde se encontra a Igreja Matriz, e que desfilam como uma marcha seguindo a bandeira de Santo Antônio, ocorre o carregamento do "pau" por um percurso de aproximadamente seis quilômetros (...). O carregamento - que, decerto, é um dos momentos centrais da festa - reúne uma porção de homens dedicados ao esforço enorme de levar adiante, em seus braços e ombros, a condução, em direção ao local de hasteamento, de uma árvore desgalhada, cuja extensão chega a vinte e dois metros, ou mais, e o peso a aproximadamente duas toneladas, duas toneladas e meia (...). Após visível tenacidade e esforço realizado, assim como recompensado, em meio às brincadeiras de duplo sentido, ou demonstrações várias de virilidade, como nas simulações de embates corporais ou consumo 
demasiado da "cachaça do Senhor Vigário", a festa, nos dias que seguem, apresenta seu fervor religioso nos noitários e procissões até o dia 13 de junho, data em que se celebra o santo padroeiro de Barbalha (IPHAN, 2015, p. 15).

Em geral, descrições da Festa do Pau de Santo Antônio priorizam dois de seus momentos: a) a escolha e carregamento do enorme tronco de madeira dos sítios que rodeiam o centro urbano até a Praça Matriz da igreja, onde se transformará no mastro da bandeira do Santo; b) o desfile de grupos de cultura popular perfilados chamado "desfile dos Grupos Folclóricos" (ALEXANDRE; SOUZA; BEZERRA, 2013, p. 66).

Tal desfile foi implementado pela Prefeitura Municipal de Barbalha no ano de 1973 (...). Com isso, o poder público municipal afirmava buscar o resgate e a preservação das manifestações populares, ao mesmo tempo em que dava mais visibilidade à Festa de Santo Antônio, atraindo pessoas de outros lugares para a cidade durante a ocasião (Idem; Ibidem, p. 68).

Vale lembrar que a Festa toma dias e noites do centro urbano de Barbalha ao longo de treze dias seguidos, finalizando na data comemorativa em louvor ao Santo Padroeiro, dia 13 de junho. Ao longo desses dias, observa-se enorme ebulição em lugares públicos e particulares da cidade. Festas privadas, visitas dos filhos ausentes da cidade, venda de artesanato ao redor da igreja matriz, quermesses, atrações locais e nacionais apresentam-se no palco do Parque da Cidade, parques de diversão se deslocam entre festejos ocorridos anteriormente em localidades de pequeno e médio da região até a cidade de Barbalha. Esse conjunto variado de atrações mobiliza interessados, vindos de cidades e sítios ao redor, em horários e espaços distintos. Rádios, jornais impressos e televisivos noticiam anualmente a Festa. Fotógrafos de renome registram o carregamento do Pau da Bandeira e dos grupos populares ali presentes, priorizando expressões de força, embriaguez e exaustão dos corpos masculinos no ato coletivo de carregar e erguer o mastro em frente à igreja. Priorizam também imagens de pessoas negras e pardas paramentadas de acordo com as manifestações lúdicas e religiosidade capitaneadas para a Festa: penitentes, maneira o pau, grupos de reisado, vaqueiros, capoeiristas, mulheres cantadoras de Coco e tantos outros. Pesquisas acadêmicas sobre a festa se multiplicam. Visitantes ocasionais retratam a si mesmos em momentos expansivos. Jovens herdeiros e herdeiras da cidade e arredores andam a cavalo 
em meio à multidão que abarrota as ruas, demonstrando distinção social e desenvoltura no trato com o animal.

Em cada registro, sentidos de origem e localização social eliciados pela Festa são adensados, precipitando um imaginário espacial entrecruzado por marcadores de gênero.

Ferreira (2013, p. 60) descreve a Festa como uma "brincadeira de homens". Em entrevista para o cineasta Rosemberg Cariry, o memorialista local Napoleão Tavares Neves refere-se a "uma festa máscula", capaz de "criar essa aura de machismo, de masculinidade em torno do pau da bandeira (...)" Segundo Napoleão Tavares, "Uma poetisa de Barbalha (...) qualificou o pau da bandeira de símbolo fálico do homem Cariri" (NEVES apud CARIRY, 2013, p. 108).

Homens escolhem o pau, homens derrubam o pau e preparam sua "cama" para que o pau possa secar na mata. Homens carregam o pau até o centro, em um esforço transcendente. Homens organizam o levantamento do pau em uma vala cavada por homens à frente da igreja matriz. Homens organizam o levantamento do pau defronte à Igreja Matriz e, ocasionalmente, machucam-se em momentos dramáticos de vacilo, valentia e sangue imediatamente noticiados pelas mídias locais. Também são homens aqueles que bebem a Cachaça do Vigário, os penitentes, aqueles que tocam zabumbas; pifes e triângulo nas Bandas Cabaçais e que dançam o reisado. Quando carregadores pardos e negros cobertos de barro veem algum político de renome, branco; pertencente a alguma elite rural ou urbana, ele será invariavelmente colocado sobre o pau, congraçando-se e diferenciando-se dos outros homens que carregam o pau ou assistem.

Inútil dizer que tal simbolismo reaviva e perpetua lugares sociais distintos atrelados ao mundo do trabalho e circulação de homens e mulheres no mundo rural, nas sociedades da cana-de-açúcar (IRFFI, 2016; NASCIMENTO, 2012; WOORTMANN, 1987). No entanto, tal como o Pau de Santo Antônio, que deixa os sítios e cruza o limite urbano encontrando seu destino em frente ao Largo da Igreja Matriz, as simbologias de gênero parecem exigir um lugar para o feminino capaz de cruzar as fronteiras de significação entre o rural e o urbano.

Se a folclorização da Festa tensiona a centralidade narrativa entre os ritos religiosos e a ebulição social que toma as ruas, os preparos litúrgicos; a organização da quermesse; os cuidados domésticos parecem incapazes de comunicar um lugar para as mulheres desde a Festa tal como expressa a partir dos anos 1970. Poderíamos sugerir que a relação pública da presença de 
mulheres na Festa passa então a ser mediada pelo Pau de Santo Antônio, Santo Casamenteiro.

A partir de meados dos anos 1990, em participações ocasionais no cortejo do Pau da Bandeira, foi-me possível perceber um jogo feminino exemplar: mulheres jovens congraçavam-se entre si tentando furar o cerco masculino de carregadores suados ou examinando atentamente os sucessivos lugares onde, sucumbidos pelo peso do enorme tronco, os homens deixavam desabar de forma ordenada a madeira no chão. Jovens mulheres intentavam obter lascas da madeira, ora avançando com mãos sequiosas sobre a tora de madeira, ora catando seus fragmentos espalhados no caminho. O riso cúmplice era constante. Impossível dizer se o riso sinalizava ironia ou desejo de casar. Assinalava certamente o desejo de tomar lugar na Festa.

A partir de 2002, a expressão pública do lugar da mulher na Festa de Santo Antônio toma forma na "Noite das Solteironas". Ausente das pesquisas acadêmicas e demais registros da Festa até meados dos anos 2000, a manifestação vem ocorrendo no sábado que antecede o carregamento do Pau da Bandeira. Alinha as simpatias populares em torno do Santo Casamenteiro e o nome da "advogada e professora aposentada", Socorro Luna, descrita como "a solteirona mais famosa do Brasil".

(...) Ela criou a Noite das Solteironas, em 2002, unindo as simpatias pelo padroeiro junto com o tradicional Pau da Bandeira. Tem a pinga Xô Caritó, o pó Cata-Marido e um kit com a casca da madeira que serve de mastro, oração e uma fitinha dizendo "Santo Antônio, tens piedade de nós, as solteironas (RODRIGUES, 2018)" - Diz reportagem veiculada em jornal local.

A narrativa presente nos veículos de comunicação parece bastante distante da ideia de memória local comunitária, imemorial e sem autoria definida, tal qual descrito nos debates sobre identidade nacional característicos do movimento folclórico brasileiro. Parece antes apoiada em uma relação em que elites locais legitimam alegorias sobre as relações sociais ali presentes, capitaneando imagens de fácil circulação. Ao mesmo tempo, veiculam um lugar para si, para modelos de relação entre homens e mulheres, assim como projetos de bem-estar (VELHO, 1978). Vejamos alguns exemplos:

Com o subtítulo "Deu certo", a reportagem intitulada "Devoção ao Santo casamenteiro reinventa costumes em Barbalha" (RODRIGUES, 2018) narra a história de Cinara Maria Mendes, que, em 2007, tomou o chá na Noite das Solteironas: “(...) Um dos carregadores parou o percurso e jogou uma lasca da 
casca na direção da garota (...) Horas depois, na mesma rua lotada, sua mão encontrou a de Daniel Rolim, e se beijaram em seguida" (RODRIGUES, 2018). A matéria encerra o enredo dizendo que os dois se casaram em 2013. "Barbalhenses, hoje, ela é dentista e ele, advogado" (Algumas páginas antes, a mesma matéria noticia o casamento coletivo de 15 casais:

Um grande casamento coletivo será realizado, com um desfile de carros antigos, tapete vermelho, helicóptero despejando pétalas de rosas e valsa ao som da sanfona. Um luxo oferecido às pessoas que atendem dois critérios: pediram ao Santo o casório, realizando alguma simpatia, e são pobres e não têm condições de pagar. (RODRIGUES, 2018).

Tais narrativas apontam lugares sociais para homens, mulheres e sua interação, descrita como natural e complementar. Reiteram um ideal de união, pautada em profissões liberais perpetuando modelos de bem-estar. Por fim, alinham tais modelos a simbolismos presentes na Festa: o carregador, o Pau da Bandeira, a tradição das simpatias.

Distantes do discurso sobre Patrimônio, as práticas e suas formas de veiculação parecem espelhar apropriações nativas de imagens veiculadas a partir da Festa, (re)instaurando um imaginário espacial que comunica Barbalha e o Cariri como mundo rural, sinônimo de tradição.

Apropriações folclorizantes distintas são também citadas por Alexandre et al. (2013, p. 68), que afirmam que "a relação da Prefeitura com as manifestações da cultura popular local resultou em uma rápida ressignificação destas".

A Dança de São Gonçalo, por exemplo, antes realizada no Sítio Barro Vermelho em Barbalha por senhoras que honravam o santo concessor de graças e curas é atualmente praticada por alunas do ensino fundamental treinadas na escola do sítio apenas para exibição na Festa de Santo Antônio. (Idem, ibidem, p. 68).

Os autores denunciam ainda que a escolha do capitão do pau, originalmente feita pelos carregadores, tem sido realizada com "maior interferência da Prefeitura Municipal de Barbalha na celebração tem se transformado numa disputa política e nem sempre o escolhido é o preferido dos carregadores" (ALEXANDRE, SOUZA, BEZERRA, 2013, p. 59).

Escolas municipais e poderes públicos situam-se assim como artífices da folclorização da Festa, expediente bastante evidente na própria realização do cortejo de grupos populares ocorrido às manhãs de domingo, descrito na 
introdução deste artigo, que irmana penitentes, reizados, grupos de Coco e outras danças a estudantes paramentados como índios, cangaceiros e outras personagens do imaginário rural-comunitário nordestino. Como destaca o dossiê do IPHAN (2015, p. 80):

O poder milagroso do pau de Santo Antônio, além de ser, sem quaisquer dúvidas, um dos principais atrativos da festa, gera uma miríade de outras atrações, que, por vezes, circulam comercialmente por Barbalha e contribuem para imprimir o mencionado tom festivo e irreverente à cidade.

Descabido seria, no entanto, pensar que tais miríades podem ser mediadas livremente. Correspondem antes a uma gramática de disputas institucionais e hierárquicas que demonstra a complexidade da Festa e do Cariri como espaço. Tais disputas simbólicas parecem exigir o tratamento de sujeitos, territórios e localidades como todos tratados a-historicamente (CLIFFORD, 2002) a serviço da aliança entre cultura popular e território. Pode-se mesmo dizer que a experiência de patrimonialização da Festa radicaliza tais disputas, à medida que inspira usos de equipamentos públicos, tais como escolas municipais; Conselho da Mulher; Secretaria de Cultura pelos poderes locais em nome do bem patrimonializado.

Para que tal gramática possa ser percebida, faz-se necessário vislumbrar momentos em que seus termos são postos em cheque, quando a agência de sujeitos encarnados evidencia relações de apagamento. À medida que afastamos o uso a-histórico e generalizante (CLIFFORD, 2002) de categorias como região, povo ou território e permanecemos atentos aos sucessivos apagamentos ontológicos a serviço da naturalização da conjunção acima descrita, percebe-se melhor os diferentes projetos e mediadores que disputam dizibilidades sobre e a partir da região.

Ainda que reconheçamos tais disputas como a própria matéria que produz a vida social sobre a qual se dobra a antropologia, Clifford (2002) parece sugerir que através de seu tratamento poderíamos ter ganhos dialógicos que evidenciariam novas agências da escrita etnográfica. Voltemos então ao conflito social empreendido pelo Movimento de Mulheres do Cariri em sua sexta marcha, realizada em julho de 2019. 


\section{Povo, território e seus distintos agentes: etnografia da Marcha das Mulheres em Barbalha}

Na manhã de domingo, horas antes da chegada do Pau da Bandeira ao centro urbano de Barbalha, dezenas de militantes se reuniam para participar do cortejo de Grupos Populares em frente ao Solar Maria Olímpio. Bandeiras e faixas foram estendidas no chão materializando o acúmulo de marchas, eventos e demandas que constituiu a trajetória da Frente de Mulheres dos Movimentos do Cariri. A exposição de faixas sinalizava ainda a confluência entre aquele movimento e coletivos diversos articulados em todo o país. Eram 10h30 da manhã quando a professora Zuleide Queiroz disse: "É agora!". Prontamente, faixas foram distribuídas, militantes se posicionaram e seguimos o curso dos demais grupos, possivelmente entre as crianças de um grupo de lapinha e os trabalhadores rurais vestidos com trajes floridos para dançar o Maneira o Pau.

Havíamos caminhado cerca de 200 metros quando um senhor em trajes formais se dirigiu a mim para perguntar se eu era o responsável pelo grupo. A pergunta me causou estranheza, já que era óbvio que as demandas daquele coletivo ganhavam voz através do microfone alternado entre a militante negra e lésbica Veronica Isidório, a professora negra Zuleide Queiroz e a estudante de psicologia Macedônia Bezerra.

Ao longo dos próximos quarteirões, múltiplas apropriações de nossa presença nas ruas da cidade de Barbalha foram tecidas: enquanto as militantes, de microfone em punho, relembravam a perda de direitos de trabalhadoras rurais com o avanço do debate sobre reforma da Previdência pelo governo Bolsonaro ou denunciavam a ausência de equipamentos públicos onde se pudesse acompanhar os alarmantes índices de violência contra a mulher na cidade, das calçadas, o público assistia ao cortejo e aplaudia. Um pequeno agrupamento de adultos jovens brancos com chapéu de couro e barba bem aparada ensaiou o grito: "Mito! Mito! Mito!14 ", recebendo olhares enviesados de militantes em marcha e do restante do público. Enquanto isso, o porta-voz dos organizadores do cortejo de grupos populares, suando em bicas, chamava a atenção para o fato de que nós não poderíamos estar ali nas ruas junto com

\footnotetext{
14 As eleições presidenciais em 2018 foram marcadas pela polarização entre a extrema direita e grupos vinculados à esquerda, compromissados com os direitos democráticos no Brasil. O representante da extrema direita, Jair Bolsonaro, ganhou a alcunha de Mito entre seus apoiadores. Embora o candidato eleito não tenha vencido em nenhum município do estado do Ceará, Barbalha apresentou a expressiva votação de $26.08 \%$ dos votos válidos em Jair Bolsonaro.
} 
os grupos de Cultura Popular. Deveríamos andar atrás de todos eles. Não entre eles.

A ação do funcionário distinguia como unidades discretas (STRATHERN, 2001) movimentos sociais e as expressões da cultura popular re(a)presentadas no cortejo. Instaurava-se ali, portanto, a expressividade de um conflito social sobre a legitimação da rua como espaço de expressão política; do cortejo de grupos populares como manifestação folclorizante ou expressão popular e sobre os próprios limites do significado do que seria a ideia de expressão popular (BUTLER, 2018). Portanto, enquanto o movimento de mulheres estabelecia relações de continuidade entre o popular e a expressão política de demandas das populações periféricas no Ceará, o representante da organização tentava reinstaurar a função festiva-folclorizante do cortejo e a legitimação dos gestores das políticas locais e demais organizadores da Festa como ordenadores das expressões ocorridas em espaço público durante a Festa.

Cruces (1988) nos ensina que apenas muito recentemente, ainda em meados do século XIX, a ocupação das ruas por uma massa de trabalhadores com demandas específicas se legitimou como "novo repertório de ação coletiva" (TILLY apud CRUCES, 1988, p. 33). Até então (...):

(...) os modos de expressão nas ruas permaneciam atados ao folclore (ou seja, a formas tradicionais de balburdia ${ }^{15}$ ou das trupes carnavalescas que, se eventualmente se politizavam, nunca chegavam a controlar o tempo e espaço das assembleias por meio de votação), assim como a modos espontâneos e desordenados de revolta (...) (Idem, p. 34, tradução do autor).

A gramática que institui a conjunção entre cidadania; legitimação de representantes identificados com movimentos ordenados a partir de discursos específicos (PALMEIRA, 1989) e estabelece o Estado como interlocutor privilegiado das ações públicas (FACCHINI, 2012) segrega carnaval, cultura popular e expressão política. Elementos reintegrados a partir da presença da Frente de Mulheres dos Movimentos do Cariri nos cortejos em Barbalha. Para que essa conjunção seja possível, no entanto, faz-se necessário perceber o movimento de mulheres do Cariri como parte da expressão popular legitima. Nesse momento, vale retomar parte do percurso da Frente de Mulheres e sua legitimação como movimento social na região.

15 "Charivari", no original. 
Não seria incorreto dizer que a Frente é fruto de uma rede que remonta a mais de três décadas de participação e liderança política de mulheres em movimentos distintos na região. O percurso dessas lideranças é bastante diverso. Estão associados à fundação de partidos de esquerda no Cariri; movimentos em torno da moradia, educação e saúde; militância em bairros populares; experiências de trabalho junto a Cáritas-Diocesana; Comissão Pastoral da Terra; movimentos negros, entre outros. A partir de meados da década de 1990, a circulação de pessoas vinculadas às universidades públicas e particulares na região possibilitou a articulação de novas redes entre feminismos fora da região e os movimentos de mulheres que ocorriam ali anteriormente, em patente exemplo de oxigenação das militâncias locais (ZANOLLI; FACCHINI, 2012). A sequência de morte violenta de mulheres entre os anos 2001 e 2003 (MARQUES, 2013) e as lutas pela abertura das Delegacias Especiais de Atendimento à Mulher, dentre outros equipamentos públicos de combate à desigualdade de gênero na região, rearticularam esses movimentos, estabelecendo uma rede de apoio às mulheres vítimas de violência nas cidades de Crato e Juazeiro do Norte. Por fim, a visibilidade das Marchas das Vadias em Juazeiro do Norte e Barbalha nos anos de 2012, e a necessidade de estabelecer um discurso coeso com gestores e imprensa inspiraram a construção da Frente de Mulheres dos Movimentos do Cariri, tal como hoje a conhecemos.

Nesse percurso, militantes associadas a redes de debate e ação políticas distantes dali passaram a articular suas formas de pensar e atuar com outras militantes, advindas de formas de participação bastante distintas. Sonia Alvarez (2014) nos ensina que, ao falarmos em feminismo, não estamos descrevendo um referente, uma ação ou relação previamente existente no mundo. Estaríamos antes estabelecendo redes de comunicação que negociam diferenças e formas de comunicar-se na diferença a partir da ação. No ano de 2012, portanto, uma variedade de trajetórias materializadas por duas ou três dezenas de militantes equacionava redes de participação política diferentes, espraiadas em todo o país e fora dele. Ao mesmo tempo, essa Frente de diferenças era marcada pela necessidade de estabelecer demandas comuns, comunicadas para além de seus pares, nos espaços restritos existentes nos meios de comunicação de massa locais e estaduais.

Certamente essa experiência difere em muito de coletivos em grandes centros urbanos que marcam na cidade sua presença através de insígnias, bandeiras, estéticas e formas de expressão comuns que vão ganhando densidade com o convívio entre pares. A partir das tensões presentes nas 
primeiras reuniões de formação da Frente, tornou-se evidente que a tentativa de confluência de uma variedade de movimentos com origens e pertenças diversas, atritos entre lideranças, seriam mais frequentes. Questões aparentemente simples, como: Quais as principais referências teóricas desse conjunto de mulheres? Qual seu vínculo com os feminismos? A Frente pode se definir como uma frente feminista? mobilizavam afetos e redes presenciais e não presenciais bastante complexas. $\mathrm{O}$ debate, portanto, não poderia ser polarizado meramente como a oposição usual entre movimentos e Estado para a implantação de políticas institucionais; tampouco poderia ser expresso como uma tensão sobre a forma de apresentação dos movimentos na mídia. O debate mais complexo a se enfrentar se dava e se dá entre os próprios coletivos, que negociam, em ação e a partir de sua ação, qual o lugar das diferenças entre eles na coalizão formada a partir daquele ano de 2012 (ALVAREZ, 2014).

Retomando Butler (2018), a fim de instituir sua presença nas ruas e redes de comunicação, os movimentos devem inventar a si como agentes legítimos daquilo que falam e sobre o lugar a partir de onde falam. No subitem 1, mobilizamos um conjunto de signos identitários que funcionam como articuladores da textualização do Cariri como unidade. Em seguida, mostramos como esses elementos, predominantemente expressos a partir da ideia de território e cultura popular são abraçados pelo IPHAN e outras formas de perpetuação da memória coletiva a partir de mediadores distintos. Para que a Frente fale de si como movimento identificado pelo lugar a partir de onde fala, estendendo a variedade de formas de participação popular reconhecidas como feminismo (BRAH, 2006), ela se faz atravessada por esses signos. Território, Cariri e povo são signos incontornáveis presentes na gramática cotidiana da Frente. Como dissemos, trata-se de dispositivos organizadores do pensamento capazes de expressar um cenário para a ação e possibilidades de gestão dos atores nele localizados.

Assim, para se instituir como mediadora de um discurso sobre o popular que se distancie das formas usuais de expressão das relações de gênero, a Frente de Mulheres deve eliciar formas expressivas articuladas a partir de outras expressividades daquilo que é popular. Podemos perceber tais esforços a partir dos embates ocorridos nas marchas em Barbalha entre os anos de 2012 e 2013. Nesses anos, a Marcha em Barbalha foi nomeada como Marcha das Vadias. O Grupo Pretas Simoa, um dos grupos de militância negra que compunha a Frente até então, passou a criticar publicamente as ações dessa coalizão de movimentos sociais. Para as militantes do Pretas Simoa, o termo "vadia" seria incompatível com a realidade da região, marcada pela presença 
de trabalhadoras rurais, mulheres negras e pardas. A partir dessa narrativa sobre o cenário do Cariri, quem se beneficiaria ao ser chamada de vadia? Que corpos poderiam ser privilegiados pela sobreposição dos termos mulheres e vadias? Certamente, não as mulheres periféricas cujo trabalho é cotidianamente precarizado e desvalorizado ${ }^{16}$.

Em embates como esse, marcadores sociais de raça; sexualidade e origem social materializados continuamente pela presença das militantes que empunham os microfones em atos públicos como as Marchas das Mulheres em Barbalha, as Marchas das Mulheres Negras em Crato, nos anos de 2015, 2017 e 2019; eventos como Artefatos da Cultura Negra; ou ainda em embates com gestores públicos são formas privilegiadas de instituir novas mediações sobre a ideia de popular, tensionando dizibilidades sobre relações de gênero tal como presentes na Festa do Pau da Bandeira em Barbalha, por exemplo.

Instituído um lugar legítimo para si, equacionado com formas de percepção do popular, faz-se possível para a Frente de Mulheres ocupar as ruas.

Em uma dessas experiências de ocupação de rua, na Marcha de Mulheres ocorrida em 2018, em meio aos grupos populares ao longo da Rua do Vidéo, a Marcha passou por dois Prefeitos e um Deputado Federal com quem tentavam agendar audiências para debater pautas do movimento feminista. Em cada um desses encontros, Verônica Isidório, empunhando o microfone, relembrava ao gestor público a lista de pendências estabelecidas com o movimento durante suas campanhas ou a insuficiência dos equipamentos públicos existentes para o combate à violência de gênero. Relembrava ainda os índices de violência em Crato, Juazeiro do Norte e Barbalha, responsabilizando gestores públicos e denunciando a falta de interlocução com o movimento feminista.

Na Marcha de Mulheres em 2019 não havia gestores ao longo do percurso. Todos se encontravam no palanque assombradado no Largo da Igreja do Rosário. Diante das contínuas tentativas de interrupção da Marcha pelo funcionário da organização, as militantes com o microfone em punho passam a legitimar sua presença nas ruas para o público: "Todos os anos nós vamos sair, sim! Porque fazemos parte dessa Festa e fazemos parte desse cortejo, sim!" Bradou Verônica Isidório, fazendo-se ouvir pelo público. "Queremos aqui ressaltar a importância dessa Festa para as mulheres. Afinal, é o Santo Antônio

16 Fotos e vídeos da intervenção do grupo Pretas Simoa estão disponíveis em: https://www.facebook.com/pg/pretassimoa/photos/?tab=album\&album_id=139894865037174 0. Acesso em: 04 mar. 2020. 
o santo das mulheres! (...). Nós viemos para a Festa de Barbalha mostrar nossa indignação. Por isso estamos aqui!" - retrucou Macedônia em seguida17.

Ao chegarmos ao Largo da Igreja do Rosário, onde se encontrava o palanque com as autoridades, o cortejo foi impedido de seguir por um cordão de seguranças uniformizados. Nesse momento, o fato de o grupo de militantes estar à frente de grupos de crianças paramentadas com trajes associados à noção de cultura popular mostrou-se fundamental. Impedir a passagem da Frente era interromper a apresentação dos grupos que vinham atrás de nós, que provavelmente ensaiaram durante todo o ano para passar em frente às autoridades locais. Olhando para os lados, pude perceber membros de grupos de cultura popular apoiando a Frente com palavras de ordem e enfrentamento físico com os seguranças. A dinâmica de militantes entre partidos de esquerda, bairros periféricos precarizados, universidades, práticas e políticas culturais na Região conferia coalizão a esses participantes do cortejo, vistos pelos organizadores como distantes e distintos. Para esses militantes da cultura popular, a distinção empreendida pelos organizadores entre movimento social e cultura popular era insustentável. Após breve embate de gritos de ordem, cada militante da marcha foi tutelado por um profissional de segurança contratado, seguindo seu percurso ao longo do Largo onde estava o palanque de autoridades. Aqueles que puxaram palavras de ordem ou portaram o microfone ao longo da caminhada receberam maior atenção, a fim de garantir que não parassem em frente ao palanque, dirigindo-se diretamente às autoridades presentes, como ocorrido em anos anteriores.

Do palanque onde estava, um dos políticos bem alimentado e protegido do sol comentou que crianças que desfilavam no cortejo atrás de nós teriam pressa. Estariam com calor e fome, por isso era necessário que passássemos mais rápido. Ao nosso lado, Mães de Santo, a Catirina, dançadores e penitentes se misturavam às militantes, apoiando-nos com sua presença.

Descrita dessa maneira, a performance da Frente de Mulheres pode ser lida como uma alegoria sobre a ação articulada pelo feminismo local para ganhar visibilidade em meio ao cortejo de Cultura Popular em Barbalha. Para que essa ação seja planejada e ganhe as ruas, essas aparentes unidades discretas: Feminismo e Grupos de Cultura Popular foram elas mesmas significadas ao longo de décadas. Foram também alinhadas a ideias de território, Cariri e povo citadas em projetos distintos, como demonstrado na sessão 1 deste artigo.

\footnotetext{
17 Leandro Medeiros de Santos produziu imagens do embate aqui descrito, disponível em: https://www.facebook.com/1832035643690895/posts/2435256743368779/. Acesso em: 05 mar. 2020.
} 
Como pudemos perceber, a hoje chamada Frente de Mulheres dos Movimentos do Cariri se constituiu a partir das fricções ocorridas entre moralidades presentes na Festa de Barbalha e os ideais feministas materializados durante a Marcha das Vadias ocorrida em 2012. Em 2019, Feminismo e Grupos de Cultura Popular são lidos pelos organizadores da festa como coisas que não devem se misturar. O embate descrito confere expressão simbólica às dinâmicas dessa disputa, evidenciando como se encontram entrelaçadas com dizibilidades acionadas sobre o Cariri, a ideia de povo e suas formas de legitimação.

\section{Conclusão}

Em forma e conteúdo, a Festa de Santo Antônio em Barbalha (CE) parece evidenciar dinâmicas dos simbolismos que distinguem o Cariri cearense como espaço. A partir das picadas abertas por Turner (2005) e suas apropriações pela antropologia pós-moderna (CAVALCANTI, 2007; CLIFFORD, 2002), tomamos a forma expressiva de um conflito social para pensar a Festa como espaço privilegiado para a textualização da região e seus agentes.

Nesse percurso, evidenciamos projetos estético-políticos distintos, e muitas vezes opostos, a reiterar simbolismos persistentes de cultura popular, gênero e território. Esse conjunto dissonante parece capaz de abrigar a conjunção do Cariri como espaço, embutindo disputas definidas para além do meramente local, e por vezes, invisibilizando a experiência dos sujeitos.

Quando cotejadas as experiências de invenção do Cariri como unidade e o conflito social vivenciado entre o movimento de mulheres e organizadores da Festa, percebemos melhor que distintos elementos expressos desde o conflito constituem, eles mesmos, agentes e símbolos da textualização do espaço: a presença (multifacetada) do feminino na Festa; a ocupação da rua como performance festiva; a Festa como rito de inversão. A ideia de que simbolismos se impõem sobre sujeitos, exigindo ações; práticas e efeitos psicológicos (TURNER, 2005), aliada à intenção de evidenciar os complexos processos multivocais (CLIFFORD, 2002, p. 47) embutidos nas imagens e imaginário da Festa exigem perceber a Festa à luz da intenção dos agentes, da dinâmica dos simbolismos e das práticas de textualização do Cariri. Dentre eles, destacamos irrupções sobre a intersecção entre gênero e espaço.

Instigado pela gramática das diferenças de gênero eliciada pela Festa, o movimento de mulheres institui sua presença a partir de conexões entre os dados da violência contra a mulher; a ausência de equipamentos públicas de combate à desigualdade de gênero e a precarização da vida das populações 
periféricas da região. Desde a Marcha das Vadias, em 2012, os movimentos de mulheres articulados pela Frente testam a si mesmo como movimento e a experiência de ocupar as ruas nessa "brincadeira de homens" (FERREIRA, 2013, p. 60). A reiteração da presença da Frente de Mulheres em debates públicos no Cariri, aliada aos marcadores sociais de gênero; origem social; sexualidade e raça visíveis nos corpos das militantes, legitimam a presença dos movimentos de mulheres e sua aderência à ideia de povo, noção fundamental para a textualização do Cariri e da Festa.

Ao mesmo tempo, são as ideias de ebulição social no rito festivo e suas possibilidades de inversão que exigem das mulheres e militantes que sejam estofo da Festa, suas inversões e misturas. Também na Festa, a Frente faz-se povo. Na festa, a Frente de Mulheres ocupa a rua como mulheres. O conflito experienciado pelas mulheres nesse rito de inversão calibra nosso olhar para os elementos que hierarquizam a Festa; as ruas de Barbalha; a região, evidenciando seus termos.

A performance da Frente e o conflito dela advindo mostram que a inversão de homens negros e pardos que carregam o pau por entre o casario colonial para transformá-lo no mastro em louvor a Santo Antônio parece agora insuficiente. Para a Frente, a precariedade dos sujeitos evocados por sua presença na Festa não se restringe à sua face patrimonializada, as miríades folclorizantes por ela multiplicadas ou à vontade de casar. Em oposição à ação dos movimentos, gestores públicos, autoridades eclesiásticas e demais organizadores da Festa em Barbalha recorrem a um imaginário espacial totalizante sobre a região, folclorizado a partir de suas mediações. Para estes, a denúncia pública da situação das mulheres e populações periféricas do Cariri é incompatível com a memória oficial da Festa do Pau da Bandeira como imagem síntese do mundo rural, com seu casario colonial; monocultura de cana-de-açúcar e religiosidade popular.

Apropriações da Festa pela memória e mídia locais se entrelaçam à veiculação da figura da "solteirona" na festa, uma mulher desejosa de casar e que em nome disso faz promessas ao Santo e toma chá de lascas do Pau de Santo Antônio. A patrimonialização da festa é perpassada ainda pela mimetização de grupos populares pelas escolas locais, dando impressão de continuidade entre as práticas de lazer e religiosidade presentes nos terreiros de pequenas comunidades na Chapada do Araripe e o ensino burocratizado nas escolas do município.

Poderíamos dizer que a patrimonialização da festa e de seus personagens acessa uma romantização do mundo rural incompatível com a denúncia da 
morte de mulheres em Barbalha, embora ambos os percursos de patrimonialização da cultura popular local e da violência contra a mulher acessem a ideia de um Brasil rural, atávico e distante da urbanidade como origem de suas ações. Tensões entre mundo rural e ideais urbanos, ora romantizados pela memória local da Festa, ora denunciados pelo movimento feminista.

As friç̧ões ocorridas na Festa de Santo Antônio no ano de 2019 nos relembram, portanto, a força e reiteração de imagens que circulam em momentos em que grupos à margem do imaginário nacional brasileiro empunham símbolos diacríticos das ideias de participação, memória nacional e cidadania: fotografias como a do vaqueiro paramentado com trajes de couro sobre seu cavalo, empunhando a bandeira da diversidade na Missa do Vaqueiro em Serrita-PE (BESSA, 2016) ou de indígenas jogando futebol em frente ao Congresso Nacional (ALVES, 2014). A circulação dessas imagens é inspirada na tensão entre um ethos corporal facilmente reconhecível como estando à margem das ideias contemporâneas de cidadania, participação ou modo de produção de bens considerados modernos e objetos que se impõem como clichês de uma utopia generalizante de abrigo à diversidade de demandas compostas pela e para a nação.

A reatualização dessas imagens sobre formas e limites da gramática de participação política legitimada parecem ser tensionadas com a presença da Frente de Mulheres em Barbalha. A partir de suas ações, percebe-se que os sujeitos por ela acessados, bem como suas aparições em espaço público, estão bastante distantes de uma gramática de participação política pensada através de sujeitos intercambiáveis e equivalentes, tal como instituído em nossas reflexões usuais sobre cidadania. Paralelo a isso, fazem-nos perceber que a generificação do Estado não se limita a equipamentos de gestão da violência, família, cuidados com crianças ou idosos. Se, como demonstraram Vianna e Lowenkron (2017), o Estado inventa a si a partir da generificação de sujeitos, esses expedientes se estendem para instituições responsáveis pelo patrimônio e memória nacional. Instituem-se ainda na forma como políticas públicas legitimam a memória coletiva e suas gramáticas de gênero. 


\section{Referências}

ALBUQUERQUE JR. Durval Muniz de.

(2001). A Invenção do Nordeste e outras artes. Recife, FJN/ Ed. Massangana. São Paulo: Cortez.

ALEGRE, Sylvia Porto.

(1994). Mãos de mestre. São Paulo: Maltese.

ALEMÃ0, Francisco Freire.

(2007). Diário de Viagem de Francisco Freire Alemão: Crato- Rio de Janeiro, 1859/1960. Vol. 2. Fortaleza. Museu do Ceará/ Secretaria de Cultura do Estado do Ceará.

ALEXANDRE, Jucieldo; SOUZA, Océlio; BEZERRA, Sandra.

(2013). Festa de Santo Antônio de Barbalha; patrimônio de fé, devoção e carnavalização. In: Igor de Menezes Soares; Ítala Byanca Silva (Orgs.). Sentidos da devoção. Festa e carregamento em Barbalha. Fortaleza: IPHAN, p.44-79.

ALVAREZ, Sonia.

(2014). Para além da sociedade civil: reflexões sobre o campo feminista. Cad. Pagu, n. 43, p. 13-56.

ALVES, Joedson.

(2014). Indios jogam bola durante protesto em Brasilia e usam bola "FIFA não". Disponível em: $<$ https://noticias.bol.uol.com.br/fotos/copado-mundo/2014/05/28/indios-jogam-

futebol-durante-protesto-em-brasilia-e-usambola-fifa-nao.htm\#fotoNav=4>. Acesso em: 04 mar. 2020.

ANDERSON, Benedict.

(1989). Nação e consciência nacional. São Paulo: Editora Ática.

ANDRADE FILH0, João Evangelista.

(1991). Mestres do Juazeiro. Cotidiano e símbolo na escultura popular. Brasília, Edunb.

ASSIS, Ana Claudia de; GODOI, Rafael Felício Silva.

(2016). 0 Boletim Latino Americano de Música IV (1946): entre linhas, músicas e ideias. In: Anais do XXVI Congresso da Associação Nacional de
Pesquisa e Pós-Graduação em Música. Belo Horizonte. p.1-10.

BARROS0, Oswald.

(2013). Teatro como Encantamento - Bois e Reisados de Caretas. Fortaleza, Armazém da Cultura.

BESSA, Silvia.

(2016). O vaqueiro moderno do sertão e a bandeira gay. Disponivel em: http://blogs.diariodepernambuco.com.br/dir etodaredacao/2016/08/08/o-vaqueiromoderno-do-sertao-e-a-bandeira-gay .Acesso em: 04 mar. 2020.

BRAH, Avtar.

(2006). Diferença, diversidade, diferenciação. Cad. Pagu, n. 26, p. 329-376.

BURKE, Peter.

(1989). Cultura popular na Idade Moderna. São Paulo: Companhia das Letras.

BUTLER, Judith.

(2018). Corpos em aliança e a política das ruas. Rio de Janeiro: Civilização Brasileira.

CARIRY, Rosemberg; BARROS0, 0swald.

(1982). Cultura Insubmissa. Fortaleza, Nação Cariri Editora.

CARIRY, Rosemberg.

(2013). Festa do Pau da Bandeira de Barbalha. In: Igor de Menezes Soares; Ítala Byanca Silva (Orgs.); Sentidos da devoção. Festa e carregamento em Barbalha. Fortaleza, IPHAN, p.80- 137.

CARVALH0, Gilmar de.

(1999). Madeira Matriz. cultura e memória. São Paulo, Annablume.

CAVALCANTI, Maria Laura Viveiros de Castro; BARROS, Myriam Lins de; VILHENA, Rodolfo; MICELLI, Silvana; MELLO E SOUZA, Marina.

(2012[1988]). Os estudos de folclore no Brasil. In: Maria Laura Viveiros de Castro Cavalcanti (Org.). Reconhecimentos: antropologia, 
folclore e cultura popular. Rio de Janeiro, Aeroplano.p. 72-99.

CAVALCANTI, Maria Laura Viveiros de Castro; VILHENA, Rodolfo.

(2012 [1990]). Traçando fronteira. Florestan Fernandes e a marginalização do folclor. In: Maria Laura Viveiros de Castro Cavalcanti (Org.); Reconhecimentos: antropologia, folclore e cultura popular. Rio de Janeiro, Aeroplano. p.102-147.

CAVALCANTI, Maria Laura Viveiros de Castro.

(2007). Drama social: notas sobre um tema de Victor Turner. Cadernos de Campo, v. 16, p. 127-138.

CLIFFORD, James.

(2002). Sobre a autoridade etnográfica. In: José Reginaldo Gonçalves (Org.); A Experiência etnográfica. Rio de Janeiro, Ed. UFRJ, p. 17-62.

CLIFFORD, James.

(2002). Sobre a alegoria etnográfica. In: José Reginaldo Gonçalves (Org.); A Experiência etnográfica. Rio de Janeiro, Ed. UFRJ, p. 6399.

CRUCES, Francisco.

(1988). El ritual de la protesta em las marchas urbanas. In: Néstor Garcia Canclini (Org.); Cultura y comunicación em la ciudade de México. México, Grijalbo/Universidad Autónoma Metropolitana. p. 27-83.

FACCHINI, R.

(2012). Conexões, processos políticos e movimentos sociais. Uma reflexão teóricometodológica a partir do movimento LGBT. Advir (ASDUERJ), v. 28, p. 6-20.

FERREIRA, Gustavo Ramos.

(2013). 0 Pau de Santo Antônio de Barbalha (CE): notas e imagens de uma festa popular. Tendências. n. 7, p. 37-67.

FIGUEIREDO FILH0, J. de.

(1960). O Folclore no Cariri. Fortaleza, Imprensa universitária.

FIGUEIREDO FILH0, J.de.

(1955). As bandas cabaçais no Cariri. Itaytera, ano 01 , n. 1, p. 107- 112.
GARDNER, George.

(1942[1849]). Viagens pelo Brasil. Rio de Janeiro, São Paulo, Porto Alegre, Recife, Companhia Editora Nacional.

GONÇALVES, Marco Antônio Teixeira.

(2013). Images et Paroles dans le cordel du Nordeste brésilien. Cahiers d'Anthropologie Sociale, v. 9, p. 23-41.

GRANGEIR0, Claudia Rejanne Pinheiro.

(2013). Discurso politico no folheto de cordel. São Paulo, Annablume.

HESCHMANN, Micael. (Org.).

(2011). Nas bordas e fora do mainstream musical. São Paulo, Estação das Letras e Cores.

HOBSBAWN, Eric.

(1997). Introdução: A Invenção das tradições. In: Eric Hobsbawn; Terence Ranger (Orgs.). A Invenção das tradições. Rio de Janeiro, Paz e Terra, p. 9-23.

INSTITUTO DO PATRIMÔNIO HISTÓRICO E ARTÍSTICO NACIONAL. IPHAN.

(2015). Dossiê de Registro. Festa do Pau da Bandeira de Santo Antônio de Barbalha. Fortaleza.

IRFFI, Ana Sara.

(2016). Cabras, caboclos, negros e mulatos: escravidão e núcleos familiares no Cariri Cearense (1850-1884). AFROASIA, v. 53, p. 944.

LIMA, Francisco Assis de Sousa.

(1985). Conto popular e comunidade narrativa. Rio de Janeiro, FUNARTE.

LUNA, Edilvan.

(2018). Inscrições de discursos sobre uma região negra: a atuação política do grupo de valorização negra do Cariri (GRUNEC). Monografia de Conclusão de Curso apresentada à Universidade Regional do Cariri.

MARQUES, Roberto

(2019). Bodies and meanings in motion: Feminisms and subjects of rights in Brazilian Northeast. Anais do $53^{\circ}$ Encontro da Latin American Studies Association. Boston- MA, p. 1-17. 
MARQUES, Roberto.

(2015a). Cariri eletrônico. São Paulo, Intermeios.

MARQUES, Roberto.

(2015b). Imagens do popular no Cariri: alguma notas à luz das obras de Gerardo Sarno e J. de Figueiredo Filho. Politica \& Trabalho, n. 42, p. 355-377.

MARQUES, Roberto.

(2013). Como se faz uma região com as ideias de atraso, violência e vitimização: Gênero, agência e trânsito de mulheres no Cariri contemporâneo. In: Domingos Sávio Cordeiro (Org.); Temas contemporâneos em Sociologia. Fortaleza, Íris, p. 133- 148.

MARQUES, Roberto.

(2008). Nordestinidade, Música e Desenraizamento ou Eram os Tropicalistas Nordestinos? In: Santuza Cambraia et al. (Orgs.). Leituras sobre Música Popular. Rio de Janeiro, 7 Letras, p. 65-82.

MARTINS, Edson Soares.

(2003). 0 cordel, o homossexual e o poeta "maudito": novelo de discursos no folheto de Salete Maria e Fanka Santos. Estudos de Literatura Brasileira Contemporânea, n. 22, p. 125-136.

MELO, Rosilene Alves de.

(2010). Arcanos do verso: trajetórias da literatura de cordel. Rio de Janeiro, 7 Letras.

MENEZES, Paulo Elpídio de.

(1985). O Crato de meu tempo. Fortaleza, Ed. UFC.

NASCIMENTO, Silvana Souza.

(2012). Homem com homem, mulher com mulher: paródias sertanejas no interior de Goiás. Cad. Pagu, n. 39, p. 367-402.

NUNES, Cícera.

(2014). Os congos de Milagres: cultura e resistência negra no Cariri cearense. Revista da Associação Brasileira de Pesquisadores/as Negros/as (ABPN), v. 6, n. 13, p. 438-455.

PALMEIRA, Moacir.

(1989). Modernização, Estado e questão agrária. Estudos Avançados, v. 3, n. 7, p. 87-108.
PINHEIRO, Irineu; FIGUEIREDO FILH0, J. de.

(1953). Cidade do Crato. Brasília, Ministério de Educação e Cultura.

QUEIROZ, Ivan da Silva.

(2014). Região metropolitana do Cariri, a metrópole fora do eixo. Mercator, v. 13, n. 3, p. 93-104.

QUIRINO, Glauberto; MARQUES, Roberto; ARAÚJO, Iara Maria de

(2013). Acesso e apropriação de políticas públicas de gênero no Centro-Sul cearense. Anais do 10o. Seminário Internacional Fazendo Gênero. Florianópolis, p.01-15.

RANCIÈRE, Jacques.

(2009). A partilha do sensivel. São Paulo, EXO experimental org. Ed. 34.

RAPOSO, Paulo.

(2014). Festa e performance em espaço público: tomar a rua. Ilha, v. 16, n.2, p. 89-114.

ROCHA, Ewelter.

(2019). Benditos da Ladeira do Horto: uma breve etnografia do silêncio. Revista do Instituto de Estudos Brasileiros, n. 73, p. 64-82.

RODRIGUES, Antônio.

(2018). Devoção ao Santo casamenteiro reinventa costumes em Barbalha. Disponível em:

https://diariodonordeste.verdesmares.com.br /editorias/regiao/devocao-ao-santo-

casamenteiro-reinventa-costumes-embarbalha-

1.1944399?fbclid=IwAR1bMi24y3DlUWZRkkDL KC7FnulKP5pLn9L4V__9xcwdGk0x7lqp3ibwJX

c. Acesso em: 13 jan. 2020.

SAID, Edward.

(1990). O Orientalismo. São Paulo: Companhia das Letras.

SEMEÃ0, Jane.

(2011). Revista "Itaytera", natureza e Cariri Cearense: a (re)invenção de uma identidade (1955-1980). In: Anais do XXVI Simpósio Nacional de História. São Paulo, ANPUH-SP, v. 1. p. 01-14. 
SILVA, Rubens Alves.

(2005). Entre "artes" e "ciências": as noções de performance e drama no campo das ciências sociais. Horizontes Antropológicos. ano 11, n. 24, p. 35-65.

SLATER, Candace.

(1986). Stories on a string. The brazilian literatura de Cordel. California, University of Califórnia Press.

SOARES, Igor de Menezes; SILVA, Ítala Byanca (2013). Apresentação. In: Igor de Menezes Soares; Ítala Byanca Silva (Orgs.). Sentidos da devoção. Festa e carregamento em Barbalha. Fortaleza, IPHAN, p. 4- 9.

SOARES, Suamy.

(2017). A Experiência militante da Frente de Mulheres dos Movimentos do Cariri: As vozes que insurgiram em um Cariri que odeia as mulheres. Anais do $11^{\circ}$ Seminário Internacional Fazendo Gênero \& 13 th Women's Worlds Congress, Florianópolis, p. 1-15.

SOUZA, Océlio.

(2000). A festa do pau da bandeira de Santo Antônio de Barbalha-CE: entre o controle e a autonomia -1928-1998. Dissertação de Mestrado apresentada ao Programa de PósGraduação em História da Universidade Federal do Rio de Janeiro.

SOUZA, Océlio.

2004. A Festa do pau da bandeira de Santo Antônio de Barbalha: algumas reflexões. In: Marinalva Vilar de Lima; Roberto Marques (Orgs.). Estudos regionais: limites e possibilidades. Crato, Ceres Editora, p. 63-71.

STRATHERN, Marilyn.

(2001). The concept of society is theoretically obsolete. For the motion (1). In: Tim Ingold (0rg.). Key debates in anthropology. London, Routledge, p. 57-66.

TURNER, Victor.

(1974). O Processo ritual. Petrópolis: Vozes.

TURNER, Victor.

(1987). The Anthropology of performance. New York, PAJ.
TURNER, Victor.

(2015). Do Ritual ao teatro: a seriedade humana de brincar. Rio de Janeiro, Ed. UFRJ.

VELHO, Gilberto.

(1978). A Utopia urbana. Rio de Janeiro: Zahar.

VIANA, José Ítalo Bezerra.

(2014). A "tendência ardorosa de cratizar o Cariri": escrita da história e representações do passado na produção do Instituto Cultural do Cariri. Revista Historiar , v. 6, p. 81-97.

VIANNA, Adriana; LOWENKRON, Laura.

(2017). 0 duplo fazer do gênero e do Estado: interconexões, materialidades e linguagens. Cad. Pagu, n. 51, e175101, 2017.

VIEIRA, Sulamita.

(2000). O sertão em movimento: a dinâmica da produção cultural. São Paulo: Annablume.

VILHENA, Rodolfo

(1997). Projeto e missão: o movimento folclórico brasileiro. Rio de Janeiro, Funarte/ Fundação Getulio Vargas.

WOORTMANN, Klaas.

(1987). Com Parente não se Neguceia: o campesinato como ordem moral. Anuário Antropológico, v. 87, p. 11-73.

YÚDICE, George.

(2013). A Conveniência da cultura. Belo Horizonte, UFMG.

ZANOLLI, V.; FACCHINI, R.

(2012). Conexões, atores, políticas sexuais e cidades. Ponto Urbe, v. 10, p. 1-20.

\section{Recebido em}

março de 2020

\section{Aprovado em}

outubro de 2020 